\title{
Evaluation of medication errors in pediatric patients using antibiotics
}

\author{
Nesligül Özdemir ${ }^{1 \oplus}$, Emre Kara $^{1 \oplus}$, Ayşe Büyükçam ${ }^{2 \oplus}$, Kübra Aykaç $^{2 \oplus}$, \\ Ayçe Çeliker ${ }^{1 \oplus}$, Kutay Demirkan ${ }^{1 \oplus}$, Ateş Kara ${ }^{2 \oplus}$ \\ ${ }^{1}$ Department of Clinical Pharmacy, Hacettepe University Faculty of Pharmacy, Ankara; ${ }^{2}$ Department of Pediatric Infectious Diseases, \\ Hacettepe University Faculty of Medicine, Ankara, Turkey.
}

\begin{abstract}
Background. Medication errors are frequently seen in pediatric patients. Medication error studies on pediatric cases were found to not only be limited but also the collaboration of clinical pharmacists and physicians on this topic was not published in Turkey. This study aimed to identify drug-related problems, especially in antibiotics.

Methods. This study was a point prevalence study with pediatric inpatients that used at least one antibiotic at a pediatric tertiary care reference hospital on November 16, 2016. Medications of patients were evaluated by clinical pharmacists in terms of drug-related problems and by physicians in terms of correct indications.

Results. Eighty-nine hospitalized patients were using antibiotics at the time of the study. The median age was 42 months (range: 1-226 months), and 49 (55.1\%) of the patients were male. Clinical pharmacists detected a total of 210 potential drug-drug interactions in $46(51.7 \%)$ patients. Approximately $48.5 \%$ of the patients in pediatric wards and $52.4 \%$ of the patients in surgical wards had at least one potential drug-drug interaction. A total of 39 medication errors were identified in 36 patients' drug orders. Most of the errors (51.3\%) were due to dosing and administration time errors (35.9\%). The number of errors per patient in surgical services was higher $(0.47)$ than the pediatric services (0.42). Forty-three percent of errors were antimicrobial-related, and $70.5 \%$ of them were classified as dosing errors.
\end{abstract}

Conclusions. Evaluation of patients' drug usage by a clinical pharmacist in terms of drug-related problems such as drug interactions, side effects and prescribing errors leads to better pharmaceutical care.

Key words: antibacterials, clinical pharmacist, medication errors, pediatrics.

Medication error is defined as 'a failure in the treatment process that leads to or has the potential to lead to harm for the patient'. ${ }^{1}$ These errors occur during prescribing, preparing, and administering medications and are frequently seen and increase the likelihood of undesirable effects in patients. ${ }^{2}$ In the United States and

\section{Nesligül Özdemir}

nesligul.ozdemir@hacettepe.edu.tr

Received 13th September 2019, revised 31st May 2021, accepted 19th June 2021.

A part of this study was presented as a poster presentation at the $35^{\text {th }}$ Annual Meeting of the European Society for Pediatric Infectious Diseases, May 23-27, 2017 Madrid, Spain.
Europe, medication errors are still a common problem in primary and secondary care centers and they cause high rates of mortality and morbidity. ${ }^{3}$

Many studies evaluating medication errors for adult patients are available in the literature however, the number of studies regarding pediatric cases is limited. ${ }^{3}$ Studies have shown that pediatric patients are exposed to 3 times more medication errors than adults. ${ }^{4}$ In pediatric patients, the most frequent medication errors are dosing errors which are commonly seen in antibiotic usage. ${ }^{2,3,5,6}$ This type of medication error is due to many factors such as a child's age, weight, body surface area, individual differences, and underlying diseases. ${ }^{3}$ 
The development of organs in pediatric patients continues for many years and the organs responsible for drug metabolism and elimination have not yet reached full capacity during neonatal and early infancy. These reasons increase the risk of injury resulting from medication errors compared to adult patients. ${ }^{7}$ Therefore, prevention of medication errors in pediatric patients is an important issue. There are too few studies in Turkey regarding the detection of medication errors in pediatric patients. ${ }^{8-10}$ However, within our knowledge, there are a few studies conducted by clinical pharmacists and physicians together. ${ }^{11,12}$

The study aims to identify medication errors using drug-related problems classification through a collaboration of clinical pharmacists and physicians in pediatric patients that received at least one antibacterial drug.

\section{Material and Methods}

This point prevalence study was conducted at a pediatric tertiary care reference hospital on November 16, 2016. The hospital is a tertiary care reference hospital with 250 pediatric neonatal acute care and intensive care beds and has 215,000 admissions per year. Within the scope of the clinical pharmacy graduate program, clinical pharmacy students have been participating in physician visits in certain services and carrying out clinical pharmacy activities in the hospital since 2014. Ethical approval for this study was obtained for retrospective evaluation of routine clinical pharmacy services performed during rotation in the pediatric infection service with the point prevalence method. The patients taking at least one antibacterial drug on the study day were included in the study. Patients in the pediatric oncology service and bone marrow transplant unit were excluded because of their treatment protocols. Patients' orders were examined in terms of medication errors and analysis and evaluation of errors were done retrospectively. Antimicrobials incorporate antibacterial, antifungal, and antiviral drugs were studied..$^{13}$
Drug indications were evaluated by 3 pediatric infectious diseases physicians whereas drug doses, administration times, and drug-drug interactions were evaluated by 2 clinical pharmacists through the electronic database system, drug orders, and nurse forms. Physicians were informed about drug-related problems identified by clinical pharmacists.

Antibiotic treatments that are not among the first or alternative treatment options in national and international guidelines for the treatment of the patient, or that are not specific to the microorganism, although the causative microorganism has been demonstrated by culture, or that are inappropriate due to patient age or that should not be preferred due to the patient's special conditions (drug reaction or allergy) were considered as not appropriate in terms of indication. The choice of antibiotics, which are not among the first or alternative treatment preferences in international and national treatment recommendations, but are among the antibiotics that can be used for the spectrum of the microorganism and possible diagnosis or the use of age-restricted antibiotic therapies in children with borderline age were considered acceptable in terms of indication.

Appropriateness of doses was evaluated according to the indications in The Harriet Lane Handbook (20th Edition, 2015, Elsevier-Saunders) and as a reference. ${ }^{14}$ Updated literature data was also used for the evaluation of doses if necessary from Up-todate and Nelson Textbook of Medicine $20^{\text {th }}$ Edition. ${ }^{15,16}$ For potential drug interactions, the Micromedex Solutions ${ }^{\circledR}$ database 'Drug interactions' section was used. Interactions are rated as contraindicated, major, moderate, and minor. In this database, contraindicated interaction means the drugs are contraindicated for concurrent use, major interaction means the interaction may be life-threatening and/or require medical intervention to minimize or prevent serious adverse effects, moderate interaction means the interaction may result in exacerbation of the patient's condition and/or require an alteration in therapy, minor interaction means the interaction 
would have limited clinical effects, manifestations may include an increase in the frequency or severity of the side effects but generally would not require a major alteration in therapy. ${ }^{17}$ Drug package inserts were also used as a reference for drug interactions.

Medication error is one of the drug related problems and they were evaluated within the scope of the drug-related problems (DRPs). A DRP is defined as an event or circumstance involving drug therapy that actually or potentially interferes with desired health outcomes by Pharmaceutical Care Network Europe (PCNE).

Drug-related problems were classified according to PCNE classification v7.0. ${ }^{18}$ This classification categorizes problems, causes of problems, interventions (the suggestion made by the pharmacist for the solution of the problems), acceptance of interventions (acceptance of the suggestion by the physician), and outcome of interventions (status of implementation of the suggestions). Dosing error is defined as a too low dose (a dose lower than the dose required for the indication) or too high dose (a dose higher than the dose required for the indication or higher than the maximum daily dose for the patient) and drug administration time error is defined as inappropriate timing of administration and/or dosing intervals according to PCNE classification v7.0.

The study was approved by Hacettepe University Ethics Board for Non-Interventional Studies Ethics Committee (date: January 17, 2017, decision number: GO 17/73-25).

Informed consent was not obtained because it was a retrospective observational study, personal data of patients were not used and clinical pharmacists did not make any intervention to patients directly. Following detection of problems, the primary physician of the patient was verbally informed by the clinical pharmacist of the problems and potential solutions determined together with the infectious disease specialist for the detected problems. The physician implemented the suggestions she/he found appropriate (such as dose change, administration time change, drug discontinuation, drug addition).

Mean and standard deviation (SD) were used for data of a normal distribution and median and minimum-maximum were used if the data have a non-normal distribution. A chi-square test was performed to compare categorical variables. Mann-Whitney $U$ test was used for the comparison of continuous variables considering the number of data. SPSS v23.0 was used for statistical analysis.

\section{Results}

At the time of the study day, there were 138 patients in the hospital. Eighty-nine (64.4\%) of them were on antibiotic treatment during the study and all of them were included in this study. Included patients' median age was 42 months (range 1-226 months) and 49 (55.1\%) of them were males.

Twenty-one (23.6\%) patients in surgical services (pediatric surgery, neurosurgery, neurosurgery intensive care unit, and cardiovascular surgery); and $68(76.4 \%)$ patients in non-surgical services (pediatric infectious diseases, newborn infectious diseases, hematology, pediatric intensive care unit, adolescent and urology) were evaluated.

Two of these patients (2.2\%) were using antibiotics for prophylaxis and all others were on the treatment protocol (Table I). Thirty-two patients $(36 \%)$ were hospitalized for suspected bacterial infection and 17 patients (19.2\%) for bacterial pneumonia according to their primary hospitalization indication.

The total different types of medications in non-surgical services $[\mathrm{n}=9$ (range $=1-24)]$ was significantly higher than surgical services $[\mathrm{n}=$ 4 (range $=1-13)](p=0.032)$. The median number of antimicrobial drugs used in surgical services was 2 (range=1-3) and in non-surgical services was also 2 (range $=1-8$ ). There was no statistically 
significant difference between surgical and non-surgical services in terms of the number of antimicrobials $(\mathrm{p}=0.956)$ and antibacterial $(\mathrm{p}=0.909)$ drugs. Thirty-two $(36 \%)$ patients were on one, $25(28.1 \%)$ patients were on 2 and $15(16.9 \%)$ patients were on 3 antimicrobial drugs, and the number of antimicrobial drugs ranged from 1 to 8 . The most commonly used three antibiotic groups were broad-spectrum penicillins $(14.9 \%)$, glycopeptides $(13.4 \%)$, and carbapenems (13.4\%) (Table I).

On the day of the study, clinical pharmacists identified 39 medication errors in 36 (40\%) patients and the number of DRPs per patient was 1.08 (Table II). Twenty (51.3\%) of these errors were due to dosing errors and $14(35.9 \%)$ of them were administration time errors ( 3 of them were inappropriate dosing intervals; and 11 were inappropriate timing of administration). Seven $(35 \%)$ of the dosing errors were due to a higher amount per dose administration and the rest of them were lower doses per patient's weight regarding the indication. The number of errors per patient in surgical services was found to be higher $(0.47)$ than the number of errors per patient in non-surgical services (0.42) but this difference was not statistically significant $(p>0.05)$. Forty-three percent of the errors were antimicrobial related, and $70.6 \%$ of them were dosing errors, $17.6 \%$ of them were timing errors and $11.8 \%$ of them were drug-drug interactions.
A total of 210 drug-drug interactions were detected in 46 patients $(51.7 \%)$. Ninety-one $(43.3 \%)$ of them were related to antimicrobial drugs in $35(39.3 \%)$ patients. The most common potential interactions were due to fluconazole (23 interactions, 25\%), ciprofloxacin (18 interactions, $19 \%$ ), and amikacin (10 interactions, $11 \%$ ). Approximately $48.5 \%$ of the patients in non-surgical and $52.4 \%$ of the patients in surgical services had at least one drug-drug interaction and overall there was no statistical difference between the services $(p=0.807)$. The significance of drug interactions detected in our study is summarized in Table III.

In surgical services, there were 21 patients, indications of antimicrobials in 10 patients (47.6\%) were not appropriate, and even though 1 of them $(4.8 \%)$ was regarded as acceptable based on personal experience of pediatric infectious disease specialist.

In non-surgical pediatric services, 9 (13.2\%) patients' antimicrobial indications were not appropriate and $9(13.2 \%)$ patients' indications were considered as acceptable out of 68 patients. The percentage of inappropriate indications in surgical services was significantly higher $(\mathrm{p}=0.006)$.

When the drug-related problems were classified according to PCNE classification, $87.2 \%$ of the errors were determined as the effect of drug

Table I. Indications of antimicrobials.

\begin{tabular}{lccc}
\hline Diagnoses & Surgical Services, $\mathrm{n}(\%)$ & Non-Surgical Services, $\mathrm{n}(\%)$ & Total, $\mathrm{n}(\%)$ \\
\hline Blood stream infections & $9(42.8)$ & $23(33.8)$ & $32(36.0)$ \\
Bacterial pneumonia & $4(19.0)$ & $13(19.2)$ & $17(19.2)$ \\
Urinary tract infections & $3(14.3)$ & $9(13.2)$ & $12(13.5)$ \\
Soft tissue infections & $3(14.3)$ & $7(10.3)$ & $10(11.2)$ \\
Meningitis & $1(4.8)$ & $7(10.3)$ & $8(9.0)$ \\
Osteomyelitis & $1(4.8)$ & $2(2.9)$ & $3(3.4)$ \\
Fungal infections & $0(0.0)$ & $2(2.9)$ & $2(2.2)$ \\
Prophylaxis & $0(0.0)$ & $2(2.9)$ & $2(2.2)$ \\
Myocarditis & $0(0.0)$ & $1(1.5)$ & $1(1.1)$ \\
Tuberculosis & $0(0.0)$ & $1(1.5)$ & $1(1.1)$ \\
Viremia & $0(0.0)$ & $1(1.5)$ & $1(1.1)$ \\
Total & $21(100)$ & $68(100)$ & $89(100)$ \\
\hline
\end{tabular}


Table II. Distribution of medication errors.

\begin{tabular}{lccc}
\hline Medication error type & Surgical Services, $\mathrm{n}(\%)$ & Non-Surgical Services, $\mathrm{n}(\%)$ & Total, $\mathrm{n}(\%)$ \\
\hline Dosing & $8(80)$ & $12(41.4)$ & $20(51.3)$ \\
Administration time & $0(0.0)$ & $14(48.3)$ & $14(35.8)$ \\
Drug-drug interactions & $1(10.0)$ & $2(6.9)$ & $3(7.7)$ \\
Drug- laboratory interactions & $1(10.0)$ & $0(0.0)$ & $1(2.6)$ \\
Duplication & $0(0.0)$ & $1(3.4)$ & $1(2.6)$ \\
Total & $10(25.6)$ & $29(74.4)$ & $39(100)$ \\
\hline
\end{tabular}

Table III. Number of drug-drug interactions per rates of interaction and per patient.

\begin{tabular}{lllll}
\hline & & Surgical Services, $\mathrm{n}(\%)$ & Non- Surgical Services, $\mathrm{n}(\%)$ & Total, $\mathrm{n}(\%)$ \\
\hline Contraindicated & Interactions & $0(0.0)$ & $9(5.0)$ & $9(4.3)$ \\
\multirow{3}{*}{ Major } & Patients & $0(0.0)$ & $7(7.9)$ & $7(7.9)$ \\
\multirow{4}{*}{ Moderate } & Interactions & $12(41.4)$ & $76(42.0)$ & $88(41.9)$ \\
& Patients & $5(5.6)$ & $26(29.2)$ & $31(34.8)$ \\
\multirow{3}{*}{ Minor } & Interactions & $11(37.9)$ & $81(44.7)$ & $92(43.8)$ \\
& Patients & $5(5.6)$ & $29(32.6)$ & $34(38.2)$ \\
& Interactions & $6(20.7)$ & $15(8.3)$ & $21(10.0)$ \\
& Patients & $5(5.6)$ & $9(10.1)$ & $14(15.7)$ \\
\hline
\end{tabular}

treatment is not optimum' under the problem section, $35 \%$ of the problem causes were classified as 'inappropriate drug administration time or interval'. Fifty-one percent of the interventions for preventing errors were 'changing the drug dose', $82 \%$ of the interventions were accepted by physicians and fully implemented and $69 \%$ of the identified problems were completely resolved (Table IV).

\section{Discussion}

In this study, drug orders of pediatric inpatients who were on antibacterial drugs were evaluated by the point prevalence method in terms of medication errors. In a point prevalence study by Grohskopf et al. ${ }^{19}, 54.4 \%$ of the patients in pediatric wards and intensive care units were using at least one antimicrobial. In a study conducted by Gerber et al. ${ }^{20}$, it was found that $60 \%$ of pediatric inpatients were using antimicrobial drugs. Compared with the literature, the antimicrobial drug usage rate was found slightly higher (64.4\%) in our study.

In our study, $51.7 \%$ of the patients were found to have at least one potential drug interaction.
In two other studies conducted on pediatric patients, drug interaction was seen in $45,8 \%$ and $49 \%$ of the patients, and of those; $0 \%$ and $5 \%$ of the patients had contraindicated, $10 \%$ and $41 \%$ of them had major, $28 \%$ and $51 \%$ of them had moderate, $11 \%$ and $39 \%$ of them had minor interactions. Also, most of the drug interactions were related to antibiotics (14.8\% and $17 \%){ }^{21,22}$ In our study antimicrobial drugs accounted for $43.3 \%$ of drug interactions and this ratio was quite high compared to the literature.

Forty-seven percent of the patients in the surgical service, $13 \%$ of the patients in the pediatric services $(21.3 \%$ of the patients in total) prescribed antimicrobial drugs were inappropriate for stated indication. In the study of Thiruthopu et al. ${ }^{23} 53 \%$ of the prescribed drugs were found to be 'most appropriate' and the rest were 'eligible'. Compared to the study of Thiruthopu et al. ${ }^{23}$ appropriateness of antibiotic indication was higher $(78.7 \%$ vs $53 \%$ ) in our study. Ceyhan et al. ${ }^{24}$, evaluated the appropriateness of indications for antimicrobials in a point prevalence study including 12 pediatric hospitals and they were found that $54.6 \%$ of 1,302 patients had at least 
Table IV. Distribution of drug related problems according to PCNE classification V7.0.

\begin{tabular}{|c|c|}
\hline Classification & $\mathrm{n}(\%)$ \\
\hline \multicolumn{2}{|l|}{ Problems } \\
\hline Effect of drug treatment not optimal & $34(87.1)$ \\
\hline No effect of drug treatment/ therapy failure & $4(10.3)$ \\
\hline Unnecessary drug-treatment & $1(2.6)$ \\
\hline \multicolumn{2}{|l|}{ Causes } \\
\hline Inappropriate timing of administration and/or dosing intervals & $14(35.9)$ \\
\hline Drug dose too low & $13(33.3)$ \\
\hline Drug dose too high & 7 (17.9) \\
\hline No indication for drug & $4(10.3)$ \\
\hline Inappropriate duplication of therapeutic group or active ingredient & $1(2.6)$ \\
\hline \multicolumn{2}{|l|}{ The Planned Interventions } \\
\hline Dosage changed & $20(51.3)$ \\
\hline Instructions for use changed & $15(38.5)$ \\
\hline Prescriber informed only & $3(7.7)$ \\
\hline Drug stopped & $1(2.6)$ \\
\hline \multicolumn{2}{|l|}{ Acceptance of the Intervention proposals } \\
\hline Intervention accepted and fully implemented & $32(82.1)$ \\
\hline Intervention accepted, implementation unknown & $5(12.8)$ \\
\hline Intervention not accepted: not feasible & $1(2.6)$ \\
\hline Intervention proposed, acceptance unknown & $1(2.6)$ \\
\hline \multicolumn{2}{|l|}{ Outcome of intervention } \\
\hline Problem totally solved & $27(69.2)$ \\
\hline Problem status unknown ${ }^{a}$ & $11(28.2)$ \\
\hline No need or possibility to solve problem & $1(2.6)$ \\
\hline
\end{tabular}

aProblem status unknown because the implementation of the interventions can't be followed or the patients are discharged.

one antimicrobial usage. In $46.7 \%$ of patients using antibiotics, an inappropriate indication was detected. The percentage of inappropriate indications in surgical services was found to be higher $(80.2 \%)$ compared to other services. Compared with the study by Ceyhan et al. ${ }^{24}$, the incidence of inappropriate indication was lower in our study in surgical services however it was higher in the surgical services compared to other pediatric services in both studies.

Although only antibacterial prescribed patients were evaluated in our study, at least one medication error was detected in $40 \%$ of the patients. Forty-three percent of the errors were related to antimicrobials. The number of medication errors in non-surgical services was found to be higher than in surgical services but the number of medication errors per patient was higher in surgical services. In pediatric patients, drug-related problems are frequently encountered due to many different causes. ${ }^{25-28}$ Approximately half of the errors were due to dosing error and $35 \%$ of the dosing errors were related to administration time, the rest of them were high or low doses in our study.

The number of patients that had experienced errors during their drug treatment was higher in our study compared to the literature $(40 \%$ vs $3-37 \%) .{ }^{6}$ In our study, the most frequently observed errors were dose errors and incorrect time of drug administration and they were similar to the literature. ${ }^{6,26,29}$ Antimicrobial drug error rates were similar to those of previous studies. ${ }^{5,30}$ In other studies, medication errors 
were detected mostly in pediatric intensive care units, but in our study, it was seen mostly in non-surgical services. ${ }^{26,29}$

According to PCNE version 7.0, half of our interventions were 'changing the drug dose'. Most of the remaining interventions were related to the modification of the drug instructions. This shows that most of the errors are made in relation to the doses of drugs and necessary precautions must be taken in this regard. To our knowledge and our literature review, the PCNE classification system was used in a small number of studies of pediatric patients in Turkey and our study is among them.

This study has some limitations; firstly, since it was a one-day point prevalence study, the study population was small. There were no control groups. Only, medication errors of patients using antibacterial medications were evaluated. The consequences of errors or interventions on the patient could not be evaluated.

In pediatric patients, medication errors occur frequently. The participation of clinical pharmacists in the multidisciplinary team is beneficial in the detection, prevention, and reduction of medication errors. The PCNE classification system is useful in classifying drug-related problems and clinical pharmacy activities. It will be more meaningful to show the impact of the clinical pharmacist when further studies are conducted with more patients over a longer period of time. It is possible to obtain more accurate and homogenous results by taking all the patients, not only those who use antibacterial.

\section{Ethical approval}

Hacettepe University Ethics Board for Noninterventional Clinical Studies approved the study (Approvel date: January 17, 2017, decision number: GO 17/73-25).

\section{Author contribution}

The authors confirm contribution to the paper as follows: study conception and design: NÖ,
$\mathrm{EK}, \mathrm{AB}, \mathrm{AÇ}, \mathrm{KD}, \mathrm{AK}$; data collection: NÖ, EK, $\mathrm{AB}, \mathrm{KA}$; analysis and interpretation of results: $\mathrm{NÖ}, \mathrm{EK}, \mathrm{AB}, \mathrm{KA}, \mathrm{AÇ,} \mathrm{KD}, \mathrm{AK}$; draft manuscript preparation: NÖ, EK, AÇ, KD, AK. All authors reviewed the results and approved the final version of the manuscript.

\section{Source of funding}

There are no sources of financial assistance in this study

\section{Conflict of interest}

The authors declare that there are no conflicts of interest.

\section{REFERENCES}

1. Ferner RE, Aronson JK. Clarification of terminology in medication errors: definitions and classification. Drug Saf 2006; 29: 1011-1022. https://doi. org/10.2165/00002018-200629110-00001

2. Tobaiqy M, Stewart D. Exploring health professionals' experiences of medication errors in Saudi Arabia. Int J Clin Pharm 2013; 35: 542-545. https://doi.org/10.1007/s11096-013-9781-0

3. Ghaleb MA, Barber N, Franklin BD, Yeung VW, Khaki ZF, Wong IC. Systematic review of medication errors in pediatric patients. Ann Pharmacother 2006; 40: 1766-1776. https://doi.org/10.1345/aph.1G717

4. Ferranti J, Horvath MM, Cozart H, Whitehurst J, Eckstrand J. Reevaluating the safety profile of pediatrics: a comparison of computerized adverse drug event surveillance and voluntary reporting in the pediatric environment. Pediatrics 2008; 121: e1201-e1207. https://doi.org/10.1542/peds.2007-2609

5. Al-Jeraisy MI, Alanazi MQ, Abolfotouh MA Medication prescribing errors in a pediatric inpatient tertiary care setting in Saudi Arabia. BMC Res Notes 2011; 4: 294. https://doi.org/10.1186/1756-0500-4-294

6. Zeleke A, Chanie T, Woldie M. Medication prescribing errors and associated factors at the pediatric wards of Dessie Referral Hospital, Northeast Ethiopia. Int Arch Med 2014; 7: 18. https:// doi.org/10.1186/1755-7682-7-18

7. The Joint Commission. Preventing pediatric medication errors. 2008. Available from: https:// www.jointcommission.org/-/media/tjc/documents/ resources/patient-safety-topics/sentinel-event/sea39-ped-med-errors-rev-final-4-14-21.pdf (Accessed on 12 January 2017). 
8. Baser S, Manav G. Çocuk hemşirelerinin ilaç hatası yapma durumları ve eğilimlerinin incelenmesi. Çukurova Üniversitesi Sağlık Bilimleri Dergisi 2018; 7: 41-49.

9. Bilsin E. Investigation of medication errors witnessed by intern nurses during pediatric practices. Arch Health Sci Res 2020; 7: 116-122. https://doi. org/10.5152/ArcHealthSciRes.2020.596887

10. Gök D, Yıldırım Sarı H. Pediyatride ilaç hataları ve hata bildirimi. İzmir Dr. Behçet Uz Çocuk Hastalıkları Dergisi 2016; 6: 165-173.

11. Ozdemir N, Celiker A, Kuskonmaz BB, Okur FV, Uckan Cetinkaya D. Evaluation of drug-related problems in a pediatric bone marrow transplantation unit identified by a clinical pharmacist in-training in a 7-month period. Clin Exp Health Sci 2020; 1: 21-26. https://doi.org/10.33808/clinexphealthsci.590213

12. Isik MN, Dalgic N, Okuyan B, Yıldız Yildırmak Z, Sancar M. Hastanede yatan pediatrik hastalarda ilaç tedavisinin incelenmesi: klinik eczacı önerileri. Çocuk Enfeksiyon Dergisi 2020; 14: 237-243. https:// doi.org/10.5578/ced.69774

13. WHO Collaborating Centre for Drug Statistics Methodology. Guidelines for ATC classification and DDD assignment, 2017. Oslo, 2016 (Accessed on 12 January 2017).

14. Tschudy MMA, Kristin M, eds. The Harriet Lane Handbook: A Manual For Pediatric House Officers (20th ed). Philadelphia, PA: Mosby Elsevier, 2012.

15. Post TW, ed. UpToDate. Waltham, MA: UpToDate Inc. Available at: https://www.uptodate.com/ contents/search (Accessed 12 January 2017).

16. Kliegman RM, Stanton B, St Geme JW 3rd, Schor NF, Behman RE, eds. Nelson Textbook of Pediatrics (20th ed). Phialdelphia: Elsevier, 2016.

17. Micromedex Solutions. Drug interactions. Available at: https://www.micromedexsolutions.com/ micromedex2/4.34.0/WebHelp/Tools/Interactions/ Drug_Interactions_severity_definitions.htm (Accessed on 8 January 2017).

18. Pharmaceutical Care Network Europe (PCNE). Classification for Drug related problems: The PCNE Classification V 7.0. Available at: http://www.pcne. org/upload/files/152_PCNE_classification_V7-0.pdf (Accessed on January 19, 2017).

19. Grohskopf LA, Huskins WC, Sinkowitz-Cochran RL, Levine GL, Goldmann DA, Jarvis WR; Pediatric Prevention Network. Use of antimicrobial agents in United States neonatal and pediatric intensive care patients. Pediatr Infect Dis J 2005; 24: 766-773. https://doi.org/10.1097/01.inf.0000178064.55193.1c
20. Gerber JS, Newland JG, Coffin SE, et al. Variability in antibiotic use at children's hospitals. Pediatrics 2010; 126: 1067-1073. https://doi.org/10.1542/peds.20101275

21. Feinstein J, Dai D, Zhong W, Freedman J, Feudtner C. Potential drug-drug interactions in infant, child, and adolescent patients in children's hospitals. Pediatrics 2015; 135: e99-e108. https://doi. org/10.1542/peds.2014-2015

22. Getachew H, Assen M, Dula F, Bhagavathula AS. Potential drug-drug interactions in pediatric wards of Gondar University Hospital, Ethiopia: a cross sectional study. Asian Pac J Trop Biomed 2016; 6: 534-538. https://doi.org/10.1016/j.apjtb.2016.04.002

23. Thiruthopu NS, Mateti UV, Bairi R, Sivva D, Martha S. Drug utilization pattern in South Indian pediatric population: a prospective study. Perspect Clin Res 2014; 5: 178-183. https://doi.org/10.4103/22293485.140558

24. Ceyhan M, Yildirim I, Ecevit C, et al. Inappropriate antimicrobial use in Turkish pediatric hospitals: a multicenter point prevalence survey. Int J Infect Dis 2010; 14: e55-e61. https://doi.org/10.1016/j. ijid.2009.03.013

25. Glanzmann C, Frey B, Meier CR, Vonbach P. Analysis of medication prescribing errors in critically ill children. Eur J Pediatr 2015; 174: 13471355. https://doi.org/10.1007/s00431-015-2542-4

26. Rashed AN, Neubert A, Tomlin S, et al. Epidemiology and potential associated risk factors of drug-related problems in hospitalised children in the United Kingdom and Saudi Arabia. Eur J Clin Pharmacol 2012; 68: 1657-1666. https://doi.org/10.1007/s00228$012-1302-x$

27. Poole RL, Carleton BC. Medication errors: neonates, infants and children are the most vulnerable! J Pediatr Pharmacol Ther 2008; 13: 65-67. https://doi. org/10.5863/1551-6776-13.2.65

28. Wilson DG, McArtney RG, Newcombe RG, et al. Medication errors in paediatric practice: insights from a continuous quality improvement approach. Eur J Pediatr 1998; 157: 769-774. https://doi. org/10.1007/s004310050932

29. Prot-Labarthe S, Di Paolo ER, Lavoie A, et al. Pediatric drug-related problems: a multicenter study in four French-speaking countries. Int J Clin Pharm 2013; 35: 251-259. https://doi.org/10.1007/ s11096-012-9740-1

30. Kaushal R, Bates DW, Landrigan C, et al. Medication errors and adverse drug events in pediatric inpatients. JAMA 2001; 285: 2114-2120. https://doi. org/10.1001/jama.285.16.2114 